\title{
EXPLORING THE EFFECT OF ORIGIN AND VARIETY ATTRIBUTES ON CONSUMERS PREFERENCES TOWARD COFFEE IN TUNISIA
}

\author{
Saida Boukriba ${ }^{\mathrm{a}}$, Yamna Erraach ${ }^{\mathrm{b} *}$
}

${ }^{a}$ Department of Agricultural Economics and Sociology, Institute of Agricultural and Fisheries Research and Training (IFAPA), P.O. Box 2027, 18080 Granada, Spain, ${ }^{b}$ Laboratory of Rural Economy, National Agronomic Institute of Tunisia INAT, University of Carthage, 43 Avenue Charles Nicolle, Tunis-Mahrajène 1082, (Tunisia).(emna_raach@yahoo.fr, boukriba.saida@gmail.com)

\begin{abstract}
Coffee consumption is increasing worldwide, particularly in non-traditional markets. In Tunisia coffee sector is evolving, offering to consumers high quality products such as specialty coffees, certified fair trade or organic coffees, coffees of origin and $100 \%$ Arabica washed coffee, etc.

In this context, the main purpose of this study is to assess consumer preferences for coffee in Tunisia.

Data were collected through a face-to-face survey, resulting in a random sample of 421 consumers. By using a structured interview and by adopting a conjoint analysis, we tested how origin, price and variety affect consumers preferences for coffee among Tunisian consumers.

Main findings of the conjoint analysis reveal that consumers attach greatest importance to "country of origin" of coffee, followed by the "variety composition", and finally by "price". Coffee from Brazil are preferred over Colombian and Ethiopian coffees. The 100\% Arabica coffee is by the most preferred over the Arabica Robusta blend.
\end{abstract}

Keys words: Consumer preference, coffee, origin, 100\% Arabica, conjoint analysis, Tunisia.

\section{Introduction}

Coffee represents one of the world's most important and heavily traded commodities. Being the pioneer of hot drinks industry in terms of value, the global consumption of coffee has known an exponential growth up to 2014 and well that it never stopped increasing (ICO, 2018). Over the last decades, coffee has gone through a transformation from a pure commodity to a specialty product, an evolution that is commonly divided into the so-called "three waves of coffee consumption" (Manzo, 2014). The two main varieties of coffee traded all over the world are Robusta (Coffea canephora) and Arabica (Coffea arabica). Robusta is a resistant variety, less susceptible to diseases, with a higher content of caffeine and lower quality than Arabica which is delicate and sensitive to climate change, but give a grain of more oval shape that presents an intense, soft and refined flavour. As for washed Arabica coffee is of highest quality, milder, and rich in flavours and aromas. In coffee year 2019/20, world global production was, according to the ICO, 169.34 million bags, with Arabica output of 95.99 million bags, accounting for around 57\% and 73.36 million bags of Robusta, representing $43 \%$ of the total. The country-of-origin hasn't received much attention in consumer research towards coffee even if this attribute can be a way of differentiating coffee roasters to target consumers, especially in the current third wave of coffee (Euromonitor International, 2017). Previous investigations, such as Sepúlveda et al. (2016), found a positive effect of Colombian origin attribute on consumer preference, while other studies such as Basu and Hicks (2008) didn't find that country of origin is an important determinant in coffee choice.

In the Tunisian coffee market, which still a developing non-traditional market, while the supplier is doubling their efforts made to be up to date with the international evolution of coffee product and to offer differentiated products to the market, the consumer does not follow the same rhythm to change his consumption behaviour. Moreover, the limited knowledge Tunisian consumers have about coffee justifies their reluctance to ask for a differentiated product and enables specialty coffees to move from a niche to a big industry.

In this sense, this study aims to understand consumer preferences and assessment of different attributes for coffee in Tunisia as a non-traditional market, and to explore the importance of origin and coffee variety attributes.

\section{Methodology}

The input data for achieving the research aims were gathered through face to-face surveys of adult consumers, resulting in a random sample of 421 Tunisian consumers met in public areas, supermarkets, entertainment spaces end coffee shops. Sample selection was conducted by stratified random sampling with proportional allocation to age, gender, and level of study to avoid under- or over-representation of some consumer profiles (Erraach et al., 2014). The questionnaire was structured into four sections: i) non 
prepared coffee buying behaviour; ii) prepared coffee consumption and knowledge; iii) washed arabica coffee consumption and knowledge; and iv) sociodemographic information of the interviewed. The questionnaire was pre-tested using 25 consumers (not included in the final sample) to check the wording, length, design of the questionnaire; and potential bias in understanding.

This study adopted Conjoint Analysis to analyse consumers preference for coffees attribute and for further investigate how origin and variety affect these preferences. Conjoint Analysis is an analytic method with decompositional approach for evaluating the preference structure of the known tastes and overall assessment (Green and Srimivasan, 1990).

The coffee attributes and their corresponding levels are

- The composition: $100 \%$ Arabica washed, 60\% Arabica washed and 40\% Robusta, 50\% Arabica washed and $50 \%$ Robusta

- The origin of the coffee: Colombia, Brazil, Ethiopia

- The price: $5.5 \mathrm{DT}^{36}, 6 \mathrm{DT}, 7 \mathrm{DT}$ (for $250 \mathrm{gr}$ ).

With 3 attributes and 3 levels per attribute, we would have $27(3 * 3 * 3)$ profiles to study too many for consumers to rate. In order to reduce the number of possible alternatives and to help respondents avoid feeling that the questionnaires were lengthy, the number of combinations was reduced by orthogonal design (Wen Wann et al., 2018) which generated 9 orthogonal arrays using SPSS 20.

The coffee profile was presented visually in the form of a card "stimuli" with a text description of hypothetical coffee. Each respondent was asked, after examining each card (coffee profile), to rate it on an interval rating scale 1 according of their preferences from 0 ("extremely dislike"), to 9 ("extremely like").

To estimate total and partial utility, an additive conjoint model was used. Moreover, the additive preference model is one of the most used models in the marketing literature, and the one that best tends to explain individuals' preferences (Hair et al., 1999). This model assumes that each level of attributes participates independently, and that the individual's total utility is the sum of the utilities of the different levels.

\section{Results}

\subsection{Sample description: Sociodemographic characteristic of respondents}

In total, 421 respondents fully completed the questionnaire. The socioeconomic characteristics of the respondents indicate that overall, 54\% of respondent are women. Regarding respondents' ages, most of them (53\%) was between 26 and 50 years old. The percentage of respondents whose monthly incomes are between 500 and 1000 DT is the highest (27\%), followed by those having between 1000 and 2000 DT/month (26\%).

\subsection{Knowledge and consumption habits}

Our results reveal that Tunisian consumers don't have enough knowledge about coffee and cannot differentiate between washed and unwashed coffee or even between Arabica and Robusta variety, since $30 \%$ only of the interviewed consumers revealed knowing the difference between both varieties, of which only $47 \%$ gave a good answer (i.e., $14 \%$ of respondents). Regarding to difference between washed and unwashed coffee, $24 \%$ only of interviewed consumers declared knowing this difference, of which $40 \%$ gave an excellent answer (i.e., $9 \%$ of respondents). In terms of consumption, Tunisian consumer only drinks an average of one cup per consumption, often at breakfast and in the afternoon, preferring three types of coffee which are Turkish coffee (62.8\%), soluble coffee (59.5\%) and filter coffee (39.9\%).

As for purchased quantity, half of the surveyed sample revealed that they buy between 250 and $500 \mathrm{~g}$ of unprocessed coffee with a frequency of purchase of once a fortnight and $9 \%$ only of respondents indicated that they buy quantities of more than $1 \mathrm{Kg}$ of coffee per purchase.

\subsection{Consumer preferences for coffee attributes in Tunisia}

Table 1 shows the aggregate preference model, including both the relative importance \% (RI) and the utilities (Ui) (part-worth) of each correspondent level.

\footnotetext{
${ }^{36}$ Tunisian dinar equivalent to 0.30 euro
} 
Table 1. The part-worths of attributes levels and the relative importance of attributes

\begin{tabular}{|c|c|c|c|c|}
\hline Attributes & $\begin{array}{c}\text { Relative } \\
\text { importance }(\%)\end{array}$ & Attributes levels & Part-worth & Standard error \\
\hline \multirow{3}{*}{$\begin{array}{l}\text { Variety } \\
\text { composition }\end{array}$} & \multirow{3}{*}{38.16} & 100\% Arabica & 0.073 & 0.12 \\
\hline & & $\begin{array}{l}60 \% \text { Arabica } 40 \% \\
\text { Robusta }\end{array}$ & 0.039 & 0.12 \\
\hline & & $\begin{array}{l}50 \% \text { Arabica } 50 \% \\
\text { Robusta }\end{array}$ & -0.112 & 0.12 \\
\hline \multirow{3}{*}{ Country of origin } & \multirow{3}{*}{41.95} & Brazil & 0.483 & 0.12 \\
\hline & & Colombia & -0.132 & 0.12 \\
\hline & & Ethiopia & -0.351 & 0.12 \\
\hline \multirow{3}{*}{ Price (DT) } & \multirow{3}{*}{19.89} & 5.5 & -0.112 & 0.104 \\
\hline & & 6 & -0.224 & 0.207 \\
\hline & & 7 & -0.335 & 0.311 \\
\hline \multicolumn{3}{|l|}{ (Constant) } & 6.828 & 0.224 \\
\hline Pearson's R & \multicolumn{2}{|c|}{0.931} & \multicolumn{2}{|c|}{ Sig. :0.000 } \\
\hline Kendall's Tau & \multicolumn{2}{|c|}{0.833} & \multicolumn{2}{|c|}{ Sig.:0.001 } \\
\hline
\end{tabular}

As shown in the table 1, consumers considered "country of origin" as the most important and preferred attribute with an importance of $41.95 \%$, closely followed by "variety composition" with an importance of $38.16 \%$. Consumers rated "price" as the third most preferable attribute with an importance of $19.89 \%$. The internal and predictive validity of the model was estimated using Pearson's R and Kendall's tau statistics, which provide measures of the observed and estimated preferences (Hair et al., 1999). As we can see in the table 1, Pearson's $\mathrm{R}=0.931$ ( $\mathrm{p}=0.000$ ) and Kendall's Tau=0.833 ( $\mathrm{p}=0.001)$ which signifies a good fit between the estimated and observed preferences.

Regarding to coffee's country of origin attribute, the Brazilian origin is the only level that has a positive and significant effect on consumers, resulting in greater probability of purchasing coffee from Brazil. At the other extreme, it was recorded that Ethiopian origin being negative its effect on consumers' utilities. With respect to variety composition our results indicate that the $100 \%$ washed Arabica is the most preferred by consumers followed by the composition of $60 \%$ Arabica with $40 \%$ Robusta, those have a positive effect on consumers utility. On the other hand, the composition 50\% Arabica with $50 \%$ Robusta is the least preferred with a negative effect on consumers utility. This result matches the findings of Lindholm and Wahlstedt (2016) indicating that in the case of Swedish consumers, 100\% Arabica coffee is more preferred than the Arabica Robusta blend.

Concerning the Price of coffee, all levels have negative coefficients, which is in accord with the demand theory as price is inversely related. The lowest the price is, the most preferred is, so 5.5 dinars has the highest effect on consumers utility followed by 6 dinars then 7 dinars. The inverse relationship between price and utility also shows that the model is consistent with the theory of consumer behavior of Lancaster (1966). Also, other studies indicate that consumer utility decreases when the coffee price increases (Asioli et al., 2014).

The aggregate utility function for the group of individuals surveyed would therefore take the form of following:

$U=6.828+[0.073 * 100 \%$ Washed Arabica $+0.039 * 60 \%$ Washed Arabica-60\%Robusta $-0.112 * 50 \%$ Washed Arabica 50\%Robusta] + [0.483* Brazil $-0.132 *$ Colombia $-0.351 *$ Ethiopia $]+[-0.112 *$ $5.5 D T-0.224 * 6 D T-0.335 * 7 D T]$.

\section{Conclusion}

In this study we analyse consumer preferences for coffee purchasing and consumption in Tunisia, especially his preferences towards composition variety and country-of-origin through the method of Conjoint Analysis. The empirical results showed that the most preferred coffee is a $100 \%$ washed Arabica coffee from a Brazilian origin and with a price of 5.5 DT per 250 grams of coffee. This means that despite of the lack of knowledge they have concerning coffee varieties and coffee products differentiation, the Tunisian consumers value $100 \%$ washed Arabica coffee variety as well as the country-of-origin attribute. This result indicates that the Tunisian market could be a potential market for high quality coffee products and there is a need to better inform this consumer on the quality differentiation attributes of coffee by specific communication strategies because generic ones are not enough. Additionally, the Tunisian coffee industry 
should focus more on the coffee variety and the country of origin to provide consumers with the products they prefer and are willing to pay for. And to do that, these results provide interesting conclusions about the sociodemographic, economic, and behavioural characteristics of coffee consumers, as well as their preferences for coffee attributes; and can be a very interesting guide to industry stakeholders to start exploring consumer decisions and choices in the coffee market and to set appropriate marketing strategies for their product to finally get higher added value to whole sector.

\section{References}

Asioli D., Boecker A., and Canavari M. (2014). "On the linkages between traceability levels and expected and actual traceability costs and benefits in the Italian fishery supply chain". Food Control, 46, 10-17.

Basu, A. K. and Hicks, R. L. (2008). "Label performance and the willingness to pay for Fair Trade coffee: A cross-national perspective". International Journal of Consumer Studies, 32(5), 470-478.

Erraach Y., Sayadi S., Gomez A.C., and Parra-López C. (2014). "Consumer-stated preferences towards Protected Designation of Origin (PDO) labels in a traditional olive-oil-producing country: The case of Spain". New Medit, 13(4):11-19.

Euromonitor International, (2017). "Repositioning Indulgence to Remain Relevant in the Healthy Snacking Era". London.

Green, P.E. and Srinivasan, V. (1990). "Conjoint Analysis in Marketing: New Developments with Implications for Research and Practice". Journal of Marketing, 54(4), 3-19.

Hair, J. F., Anderson, R. E., Tatham, R. L., and Black, W. C., (1999). Multivariate data analysis. PrenticeHall, New Jersey.

International Coffee Organization (ICO), (2018). "Emerging markets south and east Asia, September 2018". Available at: https://www.ico.org/documents/cy2017-18/icc-122-6e-emerging-markets-southand-east-asia.pdf [Accessed on 14/05/2021].

International Coffee Organization (ICO), (2015). Available at: http://www.ico.org/ [Accessed on $14 / 05 / 2021]$.

Lancaster K. J. (1966). "A New Approach to Consumer Theory”. Journal of Political Economy. 74(2), 132.

Manzo, J. (2014). "Machines, People, and Social Interaction in "third wave" coffeehouses". Journal of Arts and humanities (JAH), 3(8), 1-10.

Lindholm, R., y Wahlstedt, Y. (2016). Willingness to pay for fair trade coffee-the impact of conformity on ethical consumption. Tabajo fin de grado, Universidad de Lund, Suecia.

Sepúlveda, W. S., Chekmam, L., Maza, M. T., y Mancilla, N. O. (2016). "Consumers' preference for the origin and quality attributes associated with production of specialty coffees: Results from a crosscultural study". Food Research International, 89, 997-1003.

Wann J.W., Kao C.Y., y Yang Y.C. (2018). "Consumer Preferences of Locally Grown Specialty Crop: The Case of Taiwan Coffee". Sustainability, 10(7):2396. 